\title{
Online and Onward: Acta Medica Philippina Is Now Fully Online
}

Starting with this issue, Acta Medica Philippina is doing away with its printed copy format and is going entirely online!

What's more, we will now be putting out two issues every month. This is to be able to serve not only our UP-Manila community better but the expanding regional interests as well.

Our journal has had an online presence since 2008, but it has also continued to print hard copies. Just like its printed copies, our website has gone through several changes in its internet domains and appearances for various creative and logistical reasons through those years. Currently, it is hosted in the UP-Manila server (https://actamedicaphilippina.upm.edu.ph/ index.php/acta), an optimal arrangement, in my opinion, highlighting that UP Manila is the publisher of Acta Medica Philippina. This transition to a purely online publication strategy allows us to save on the printing costs being provided by the Dean's Office of the UP College of Medicine. Now, our College can use it instead for other purposes. By conserving paper, we also help save the environment in our little way.

Over and above these practical considerations are the longer-term benefits. Of course, online technologies and platforms have been long with us in many aspects of our personal and professional lives that justifying such an online strategy may not be needed. After all, the internet has become our go-to information resource - literally at the tips of our fingers with the help of our gadgets. Especially for us in the field of health sciences, whether in the clinical, academic, and/or policy-making spheres, updated data and scientific information are vital as bases for timely decision-making. The online approach is most suitable to promote wider and timely access, search, verification, archiving, and ascription.

There are however additional benefits for authors who are responsible for content generation in the case of scientific articles. Starting from a more personal perspective, for those in the academe and/or conducting research, a track record of publication is commonly used as criteria for the promotion of faculty and assessment of qualification to do research. An online platform allows the Journal to more immediately publish those articles that have undergone proper peer reviews and scrutiny. Peer review, among its other benefits, can help improve the quality of the written material.

Many of the indexing services (e.g., Clarivate ${ }^{\circledR}$ - formerly Web of Science (WoS) - Scopus ${ }^{\circledR}$, PubMed ${ }^{\mathrm{TM}}$, etc.) also require such publication in the online space to facilitate inclusion in their databases. Such databases allow a targeted search favored by many scientists and other researchers. By actively applying for inclusion of its articles in these databases, the Journal may achieve wider exposure of the articles within its pages. Ultimately, adding value to the scientific work of others helps justify the resources we invest in these research activities.

Google Scholar ${ }^{\circledR}$ (https://scholar.google.com/) has added another dimension useful for both authors of published articles and researchers, including students. Although it is not the same compared to the more traditional databases like Web of Science ${ }^{\circledR}$ and Scopus ${ }^{\circledR}$ (both of which are available only as paid subscriptions), Google Scholar ${ }^{\circledR}$ uses its proprietary algorithm to crawl for articles that appear in the world-wide-web. WoS and Scopus ${ }^{\circledR}$ require that journals apply and be accepted to be included in their databases. But Google Scholar ${ }^{\circledR}$ automatically does this, using its tried and tested Google search engine. A particularly useful feature of Google Scholar ${ }^{\circledR}$ is the ability to find out the number of citations of the said articles and provide these data for free. Funding agencies, among other parameters, can find these useful in identifying research areas that are most relevant and/or identify most likely researchers who are engaged in doing research in specific areas. As one of its early digital strategies, our Journal subscribed to a paid web hosting that is optimally configured for appearing on Google Scholar ${ }^{\circledR}$. Although we have since opted out of that, articles in Acta Medica Philippina now appear in Google Scholar almost as soon as it is posted online! 
But the cloud can be an "impermanent" thing. That is, a document that exists solely on the web can change its physical location. This is most commonly seen when websites change their domain names for whatever reason/s - as the case was for Acta Medica Philippina in the past. Looking for the same article can be problematic in this regard. This is where a Document Object Identifier, or doi for short, can come in. A doi is a unique and never-changing string assigned to online (journal) articles, books, and other works. Since October 2020, Acta Medica Philippina has provided a doi for the articles it posts online through CrossRef ${ }^{\circledR}$. We are currently working on securing doi for the past articles that have been published in the journal.

There are other digital strategies that Acta Medica Philippina has undertaken in recent years to fully leverage the available technology. For example, our submission, review, and production process are fully online as well for more than a year now, integrated into a single portal. This helps us to work more efficiently and remain in touch with the growing number of our stakeholders - from authors to reviewers and even copy editors and layout artists. At the same time, the publication process has become more and more complex, with evolving and stricter requirements to ensure proper ethics and integrity.

Our journal - designated as the National Health Sciences Journal - fully embraces these challenges and remains motivated to expand its capabilities. The journal staff and its Editorial Board aim to grow further the benefits to its readers and authors who choose to publish with Acta Medica Philippina.

We thank all of you for your continuing confidence and support.

Joven Jeremius Q. Tanchuco, MD, MHA

Professor, Department of Biochemistry and Molecular Biology, College of Medicine, University of the Philippines Manila Clinical Professor, Division of Pulmonary Medicine, Department of Medicine, College of Medicine and Philippine General Hospital, University of the Philippines Manila 